\title{
Women's Awareness and Associated Factors on Preconception Folic Acid Supplementation in Adet, Northwestern Ethiopia, 2016: Implication of Reproductive Health
}

\author{
Yitayal Ayalew Goshu (D), ${ }^{1}$ Tewachew Muche Liyeh ${ }^{(D)},{ }^{1}$ Amare Simegn Ayele ${ }^{D},{ }^{1}$ \\ Liknaw Bewket Zeleke $\left(\mathbb{D},{ }^{2}\right.$ and Yohannes Tesfahun Kassie $\mathbb{D}^{3}$ \\ ${ }^{1}$ Department of Midwifery, College of Health Sciences, Debre Tabor University, Debre Tabor, Ethiopia \\ ${ }^{2}$ Debre Markos University, Debre Markos, Ethiopia \\ ${ }^{3}$ Debre Tabor General Hospital, Debre Tabor, Ethiopia \\ Correspondence should be addressed to Yitayal Ayalew Goshu; ayalewyitayal@gmail.com
}

Received 12 February 2018; Revised 17 April 2018; Accepted 10 June 2018; Published 17 July 2018

Academic Editor: Michael B. Zemel

Copyright (c) 2018 Yitayal Ayalew Goshu et al. This is an open access article distributed under the Creative Commons Attribution License, which permits unrestricted use, distribution, and reproduction in any medium, provided the original work is properly cited.

Introduction. Preconception folic acid supplementation is the provision of folate for reproductive age group women who have a plan to be pregnant. According to different studies, in African countries, there is poor utilization of preconception folic supplementation. So this study aimed at assessing women's awareness on preconception care and its associated factors in Adet, Northwestern Ethiopia. Methods. A community-based cross-sectional study was conducted from March 1 to April 1, 2016, among 422 reproductive age group women. Systematic random sampling was used to get the study unit, and the data were collected using pretested structured questionnaire via face-to-face interview. The collected data were entered, cleaned, checked using EpiData version 3.1, and finally analyzed using SPSS version 20. Descriptive summary of the data was presented in terms of percentage and frequency. Binary and multiple logistic regressions were used in order to identify predictors using odds ratio at $95 \%$ confidence interval. Result. In this study, a total of 422 reproductive age group women participated with a response rate of $100 \%$. Of a total of 422 participants, 67 (15.9\%) of the women had good awareness on preconception folic acid supplementation. Women's awareness on preconception folic acid supplementation was affected by having a chronic health problem, monthly household income, educational status, and a history of family planning use. Women who were educated (AOR 4.77, CI 1.85-6.98), had a history of family planning use (AOR 3.89, CI 1.77-8.55), had a chronic health problem (AOR 3.47, CI 2.68-5.98), and had a better monthly income (AOR 2.6, CI 2.05-6.76) had good awareness than their counterparts. Conclusion and Recommendation. This study concluded that women's awareness on preconception folic acid supplementation was low. This finding suggests that there is a need to give emphasis and deliver health education about preconception folic acid supplementation for women.

\section{Introduction}

Supplementing folic acid before pregnancy is the provision of folate for reproductive age group women who have a plan to be pregnant, so that the health of women before pregnancy can be promoted and pregnancy-related outcomes can be improved $[1,2]$. Folic acid is an important substance which is grouped under essential vitamin $B$ that provides one-carbon molecules for deoxyribonucleic acid (DNA) synthesis, protein synthesis, and methylation of DNA and proteins [3]. A study, which was done to see the association between maternal folic acid intake and the risk of neural tube defects, revealed that the pathway of folic acid plays a critical role in cellular function and human development [1].

According to different interventional studies done in different countries, administering of $0.4 \mathrm{mg}$ of folic acid for the reproductive age group three months before pregnancy, during pregnancy period, and up to one month after pregnancy has been associated with up to $80 \%$ reduction in specific congenital anomalies including neural tube defects (NTDs) with associated hydrocephalus, oral facial clefts with or without cleft palate, congenital heart disease, urinary tract anomalies, and limb defects, as well as some pediatric cancers [4-11]. Many articles revealed that preconception 
folic acid supplementation is associated with increased fetal growth resulting in higher placental and birth weight, and decreased risks of low birth weight and small for gestational age [12-14]. One interventional study also revealed that the consumption of folic acid before conception can decrease the risk of developing anemia and peripheral neuropathy [15]. Despite wide availability of its natural food sources (green leafy vegetables, bananas, and legumes), folic acid deficiency among women of reproductive age is common worldwide, usually as a result of low dietary intake $[16,17]$.

Articles done in different areas revealed that women's knowledge on the role of folic acid in preventing NTDs as well as the utilization of preconception folic acid is very low [18-20]. But the prevalence of congenitally anomalies, especially neural tube defects, is a major problem worldwide. Moreover, the incidence and prevalence of neural tube defects in developing countries, including African countries, have been reported to be up to fourfold higher than those in developed ones. Different articles show that the lifelong medical and socioeconomic consequences of NTDs in affected children are well known to be worse in low-resource settings [13, 21, 22]. Studies done in developed countries such as Canada, Lebanon, and the Netherlands figured out that knowledge on preconception folic acid supplementation was $81.0 \%, 71.9 \%, 53.3 \%$, and $36.8 \%$, respectively [23-26]. But based on different studies done in developing countries such as Nigeria, Jordan, and Pakistan, women's knowledge on preconception folic acid supplementation was $25.5 \%$, $21.2 \%$, and $6.7 \%$, respectively. Moreover, the awareness of women on preconception folic acid supplementation in Ethiopia has not been studied yet [27-29].

Different articles showed that women's awareness on preconception folic acid supplementation is affected by sociodemographic characteristics (such as age, gender, educational status, ethnicity, income, and marital status) and women's reproductive history (history of pregnancy, history of family planning use, health condition, history of ANC visit, parity, and gravidity) [23-29].

Therefore, this study aimed at assessing women's awareness on preconception folic acid supplementation and associated factors in Adet, Northwestern Ethiopia, which is helpful for policy makers to allocate resources and intervene utilization and determinant factors of preconception care for improving of maternal and child health.

\section{Methods}

2.1. Setting. This community-based cross-sectional study was conducted in Adet town, which is an administrative town of Yilmana Densa Woreda and located in West Gojjam Zone, Amhara Regional State, from March 01 to 30, 2016. Adet is located 524 kilometers away from Addis Ababa (the capital city of Ethiopia) and 42 kilometers far from Bahir Dar (the capital city of Amhara Regional State) with an altitude of 2, 216 meters above the sea level. According to figures from the Central Statistical Agency in 2015, the estimated total population of the town is 42,983 . Out of this, 21,234 (49.4\%) were men and 21, 749 (50.6\%) were women. In this turn, the total number of women who were in the reproductive age group (15-49 years) were 14, 248, which accounts for $33.1 \%$ of the total population. The town has three kebeles (the smallest unit of the Woreda) and 13,515 households [30].

\subsection{Participants}

2.2.1. Source Population. All women who lived in Adet were the source of population.

2.2.2. Study Population. All reproductive age group women who lived in Adet were our study population.

2.2.3. Study Unit. Individual reproductive age group woman was our study unit.

2.3. Eligibility Criteria. All reproductive age group women who lived in Adet for 6 months and above were included.

2.4. Sample Size Determination and Sampling Procedure. The sample size was calculated by using a single-population proportion formula $=Z^{2} p(p-1) / d^{2}$, with assumptions of $50 \%$ the population proportion of women's awareness on preconception folic acid supplementation, 95\% confidence interval, marginal error of 5\% (0.05), and $10 \%$ nonresponse rate. All the three kebeles (the smallest unit of the district) were included for study. To reach the study unit, systematic sampling technique was used in all the three kebeles. The first house was selected randomly in one place and every 32nd house for all kebele was asked. The sampling interval of the households in each kebele was determined by dividing the total number of households in the specific kebele by the allocated sample size. When there was no woman in the reproductive age group in the selected house, the nearby house was asked. In case of more than one eligible woman encountered in the selected household, a lottery method was used to determine which woman would be interviewed.

2.5. Data Collection Tools and Techniques. An intervieweradministered questionnaire was developed for the purpose of data collection after reviewing relevant literature. It was prepared originally in English and was translated into local language, Amharic, for the purpose of data collection, and then it was translated back to English again for consistency and accuracy by language experts. The questionnaire had sociodemographic parts, reproductive characteristics, and questions related to preconception folic acid supplementation awareness. Face-to-face interview was carried out by three diploma nurses under the supervision of two degreeholding nurses and principal investigator for a period of one month. Training of data collectors and supervisors about purpose of study, handling of ethical issues, and data collection procedures was given for two days. In addition to this, the quality of data was ensured through pretests of 22 women, manual checkup for completeness and accuracy on a daily basis, and proper feedback by supervisor. 


\subsection{Operational Definition}

(i) Smoking status: had a history of smoking or currently smokes regardless of amount.

(ii) Alcohol consumption: intake of alcoholic drinks on days other than holidays and culturally special ceremony days.

(iii) Awareness

(a) Good awareness: a woman was considered as having good awareness if she had heard about preconception folic acid supplementation and had told the appropriate time of initiation.

2.7. Data Analysis. First, the collected data were entered, cleaned, and checked by the software EpiData version 3.1 and then exported to SPSS version 20 for analysis. Descriptive summary of different variables was presented in terms of frequency and percentage by using table and graph. Binary and multivariate logistic regressions were computed to identify predictor variables with an odds ratio at $95 \%$ confidence interval. In binary logistic regression, variables which had a $P$ value of $<0.25$ were transferred into multivariate logistic regression, and finally, variables which had $P$ value $<0.05$ in multivariate logistic regressions were considered as significantly associated with women's awareness on preconception folic acid supplementation.

2.8. Ethical Considerations. Ethical clearance was obtained from the Institutional Review Board of the College of Health Sciences, Mekelle University, and the official cooperation letter was obtained from the Amhara Regional Health $\mathrm{Bu}$ reau. Finally, the ethical clearance of this study was granted by official cooperation letter of Yilmana Densa Woreda Health Office. Participants consented to take part in the study by signing the informed consent form after they had been thoroughly briefed about the purpose of the study. Participation was on a voluntary basis after written consent, and the responses were kept confidential. The interview was carried out privately in a separate area and confidentiality was ensured through coding.

\section{Result}

3.1. Sociodemographic Characteristics. This study was carried out among a total of 422 reproductive age group women with a response rate of $100 \%$. Almost all of the participants (99.8\%) were Amhara in ethnicity, and most of the participants $(84.8 \%)$ were Orthodox Christian in religion. The median age of the participants was 25 years with an interquartile range of 11 years. $35.3 \%$ of the respondents had a monthly household income of 100 US dollar or less, and $31.0 \%$ of the respondents had high school education. More than half of the participants (59.5\%) were married and $26.8 \%$ of women were housewives (Table 1).

3.2. Reproductive Characteristics. Among a total of 422 participants, 268 (63.5\%) have been pregnant before. Among
TABle 1: Sociodemographic characteristics of women in Adet, Gojjam, Northwestern Ethiopia, $2016(n=422)$.

\begin{tabular}{|c|c|c|}
\hline Characteristics & Frequency $(N)$ & Percent (\%) \\
\hline \multicolumn{3}{|l|}{ Age } \\
\hline $15-24$ & 196 & 46.4 \\
\hline $25-34$ & 136 & 32.2 \\
\hline $35-49$ & 90 & 21.3 \\
\hline \multicolumn{3}{|l|}{ Ethnicity } \\
\hline Amhara & 421 & 99.8 \\
\hline Shinasha & 1 & 0.2 \\
\hline \multicolumn{3}{|l|}{ Religion } \\
\hline Orthodox & 358 & 84.8 \\
\hline Muslim & 60 & 14.2 \\
\hline Protestant & 4 & 1.0 \\
\hline \multicolumn{3}{|l|}{ Occupation } \\
\hline Housewife & 113 & 26.8 \\
\hline Government employee & 79 & 18.7 \\
\hline Market trade vendor & 107 & 25.4 \\
\hline Daily laborer & 28 & 6.6 \\
\hline Student & 95 & 22.5 \\
\hline \multicolumn{3}{|l|}{ Educational status } \\
\hline No formal education & 99 & 23.5 \\
\hline Primary school & 97 & 23.0 \\
\hline Secondary school & 131 & 31.0 \\
\hline College and above & 95 & 22.5 \\
\hline \multicolumn{3}{|l|}{ Monthly income } \\
\hline $50 \$$ or less & 149 & 35.3 \\
\hline $51-100 \$$ & 96 & 22.7 \\
\hline $101-150 \$$ & 55 & 13.1 \\
\hline $151-200 \$$ & 65 & 15.4 \\
\hline More than $200 \$$ & 57 & 13.5 \\
\hline \multicolumn{3}{|l|}{ Marital status } \\
\hline Married & 251 & 59.5 \\
\hline Divorced & 35 & 8.3 \\
\hline Widowed & 17 & 4.0 \\
\hline Single & 119 & 28.2 \\
\hline
\end{tabular}

those who have been pregnant before, 6 (2.2\%) of the participants had a history of preterm birth and only $5(1.9 \%)$ of the respondents had ever been given birth to a baby with congenital anomaly. Based on the respondents' parity, 154 (36.4\%), 53(12.6\%), $191(45.3 \%)$, and $24(5.7 \%)$ of the participants were nulliparous, primiparous, multiparous, and grand multiparous, respectively. The majority $(58.1 \%)$ of the respondents had a history of family planning use, and around $8.3 \%$ of respondents had chronic health problems (Table 2).

3.3. Preconception Folic Acid Supplementation Awareness. The finding of this study revealed that from a total of 422 participants, only $79(18.7 \%)$ of women have heard before about preconception folic acid supplementation. From those who have heard, the majority of the participants (60 (75.9\%)) have heard from mass media and minority $(6(7.6 \%))$ of them have heard from friends (Figure 1). Based on participants' overall awareness on preconception folic acid supplementation, only $67(15.9 \%)$ participants had good awareness (Figure 2). From those who have heard about preconception folic acid supplementation, 67 (15.9\%) 
TABLE 2: Reproductive characteristics of women in Adet, Gojjam, Northwestern Ethiopia, $2016(n=422)$.

\begin{tabular}{|c|c|c|}
\hline Variables & $\begin{array}{c}\text { Frequency } \\
(N)\end{array}$ & $\begin{array}{c}\text { Percent } \\
(\%)\end{array}$ \\
\hline \multicolumn{3}{|l|}{ Ever been pregnant? } \\
\hline Yes & 268 & 63.5 \\
\hline No & 154 & 36.5 \\
\hline Total & 422 & 100 \\
\hline \multicolumn{3}{|c|}{ History of preterm birth $(n=268)$} \\
\hline Yes & 6 & 2.2 \\
\hline No & 262 & 97.8 \\
\hline Total & 268 & 100 \\
\hline \multicolumn{3}{|c|}{ History of congenital anomaly $(n=268)$} \\
\hline Yes & 5 & 1.9 \\
\hline No & 263 & 98.1 \\
\hline Total & 268 & 100 \\
\hline \multicolumn{3}{|c|}{$\begin{array}{l}\text { Counseled about subsequent pregnancy } \\
(n=5)\end{array}$} \\
\hline Yes & 2 & 40.0 \\
\hline No & 3 & 60.0 \\
\hline Total & 5 & 100 \\
\hline \multicolumn{3}{|c|}{ Number of alive children $(n=268)$} \\
\hline$\leq 2$ & 168 & 62.7 \\
\hline$>2$ & 100 & 37.3 \\
\hline Total & 268 & 100 \\
\hline \multicolumn{3}{|l|}{ Family planning use } \\
\hline Yes & 245 & 58.1 \\
\hline No & 177 & 41.9 \\
\hline Total & 422 & 100 \\
\hline \multicolumn{3}{|c|}{ Having chronic health disease? } \\
\hline Yes & 35 & 8.3 \\
\hline No & 387 & 91.7 \\
\hline Total & 422 & 100 \\
\hline \multicolumn{3}{|c|}{ Types of health problems $(n=35)$} \\
\hline HIV/AIDS & 7 & 20 \\
\hline Hypertension & 6 & 17.2 \\
\hline Infertility & 5 & 14.3 \\
\hline Diabetes mellitus & 4 & 11.4 \\
\hline Epilepsy & 4 & 11.4 \\
\hline Renal problem & 4 & 11.4 \\
\hline Asthma & 3 & 8.6 \\
\hline Others & 2 & 5.7 \\
\hline Total & 35 & 100 \\
\hline
\end{tabular}

Others $=$ liver disease and anemia.

participants have correctly mentioned the right time of initiation for preconception folic acid supplementation (Table 3).

3.4. Associated Factors. In order to check the association between dependent variable and independent variables, first 15 variables were entered into the binary logistic regression. Then, six variables (women's age, educational status, monthly income, a history of family planning use, having a chronic health problem, and a history of pregnancy) with a $P$ value of $<0.25$ were entered into multivariate logistic regression. Finally, in multivariate logistic regression, only four variables (women's history of family planning use, household monthly income, having a chronic health

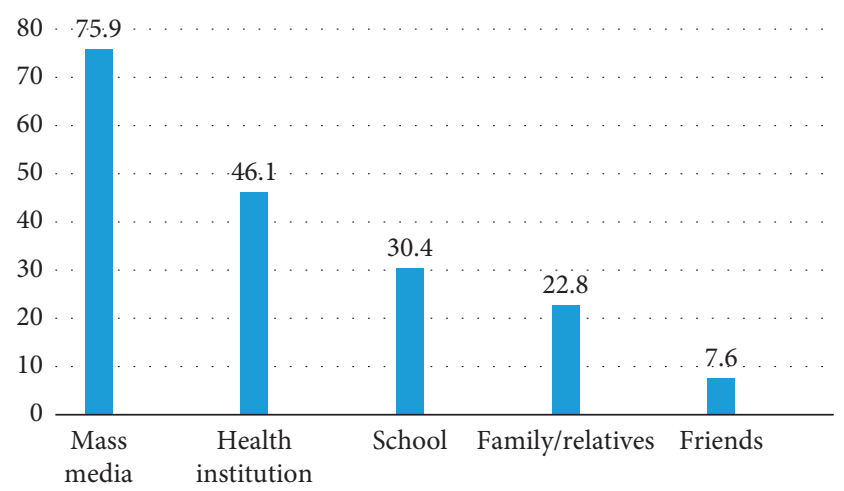

Figure 1: Women's source of information for preconception folic acid supplementation in Adet, Gojjam, Northwestern Ethiopia, $2016(n=79)$. Note that the total summation of percentage is more than $100 \%$ due to multiple answers.

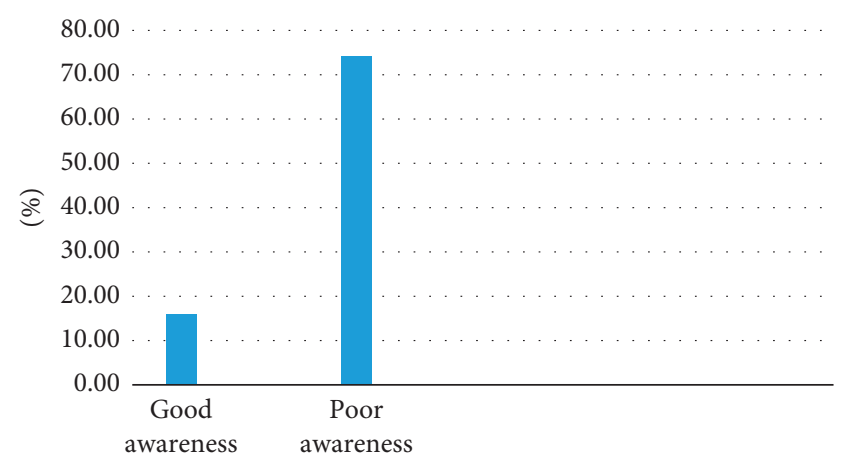

FIGURE 2: Distribution of women's overall awareness on preconception folic acid supplementation in Adet, Gojjam, Northwestern Ethiopia, $2016(n=422)$.

problem, and educational status) were statically significant $(P$ value $<0.05)$ at $95 \%$ confidence interval with women's awareness on preconception folic acid supplementation (Table 4). Women who had primary education were approximately four times more likely to have had good awareness on preconception folic acid supplementation than women who had no formal education (AOR 3.94, CI 2.564.78). Women who had a chronic health problem were more than three times more likely to have had good awareness on folic acid supplementation than women who did not have a chronic health problem (AOR 3.47, CI 2.68-5.98).

\section{Discussion}

Folic acid supplementation before pregnancy and just during postpartum period for at least four weeks helps to protect the occurrence of neural tube defects and other congenital abnormalities [8-11]. And having awareness about preconception folic acid supplementation is very important for women to start taking folic acid early.

The findings of this study revealed that sixty-seven (15.9\%) participants had good awareness on preconception folic acid supplementation. The result of this study is lower than those of many studies conducted in developed countries like Canada (81\%) [23], Lebanon 
TABLE 3: Distribution of women's awareness on the benefit and time of initiation for on preconception folic acid supplementation in Adet, Gojjam, Northwestern Ethiopia, $2016(n=422)$.

\begin{tabular}{lcc}
\hline Characteristics & Frequency $(N)$ & Percentage $(\%)$ \\
\hline Time of initiation & & 67 \\
Three months before pregnancy & 6 & 15.9 \\
One month before pregnancy & 4 & 1.4 \\
Two weeks before pregnancy & 2 & 1.0 \\
One weeks before pregnancy & 343 & 0.4 \\
Do not know & 422 & 81.3 \\
Total & & 100 \\
\hline Benefits of preconception folic acid supplementation & 35 & 8.2 \\
Prevent anemia & 18 & 4.4 \\
Prevent congenital anomaly & 15 & 3.5 \\
Prevent obstructed labor & 11 \\
Prevent weight loss & 343 \\
Do not know & 422 \\
Total & 2.6 \\
\hline
\end{tabular}

TABLE 4: Factors associated with women's awareness on preconception folic acid supplementation in Adet, Gojjam, Northwestern Ethiopia, $2016(n=422)$.

\begin{tabular}{|c|c|c|c|c|}
\hline \multirow{2}{*}{ Variables } & \multicolumn{2}{|c|}{ Awareness } & \multirow{2}{*}{ Crude odds ratio $(95 \% \mathrm{CI})$} & \multirow{2}{*}{ Adjusted odds ratio ( $95 \% \mathrm{CI})$} \\
\hline & No & Yes & & \\
\hline \multicolumn{5}{|l|}{ Educational status } \\
\hline No formal education & $90(90.9 \%)$ & $9(9.1 \%)$ & 1 & 1 \\
\hline Primary school & $82(84.5 \%)$ & $15(15.5 \%)$ & $1.83(1.096-4.813)^{* *}$ & $3.94(2.56-4.78)^{* *}$ \\
\hline Secondary school & $109(83.2 \%)$ & $22(16.8 \%)$ & $2.02(1.247-5.039)^{* *}$ & $4.05(2.79-6.94)^{* *}$ \\
\hline College and above & $74(77.9 \%)$ & $21(22.1 \%)$ & $2.84(2.577-10.633)^{* *}$ & $4.77(1.85-6.98)^{* *}$ \\
\hline \multicolumn{5}{|l|}{ Monthly income } \\
\hline $50 \$$ or less & $132(88.6 \%)$ & $17(11.4 \%)$ & 1 & 1 \\
\hline $51-100 \$$ & $85(88.5 \%)$ & $11(11.5 \%)$ & $1.01(.546-1.852)$ & $1.26(.3-1.67)$ \\
\hline $101-150 \$$ & $42(76.4 \%)$ & $13(23.6 \%)$ & $2.40(1.074-4.062)^{* *}$ & $2.62(2.05-6.76)^{* *}$ \\
\hline $151-200 \$$ & $52(80.0 \%)$ & $13(20.0 \%)$ & $1.94(.847-3.078)^{*}$ & $1.04(.38-2.80)$ \\
\hline More than $200 \$$ & $44(77.2 \%)$ & $13(22.8 \%)$ & $2.29(.793-3.072)^{*}$ & $1.50(.35-3.23)$ \\
\hline \multicolumn{5}{|l|}{ Health problem } \\
\hline Yes & $30(85.7 \%)$ & $5(14.3 \%)$ & $1.15(.792-3.353)^{*}$ & $3.47(2.68-5.98)^{* *}$ \\
\hline No & $35(73.4 \%$ & $62(16.0 \%)$ & 1 & 1 \\
\hline \multicolumn{5}{|c|}{ History of family planning use } \\
\hline Yes & $189(77.3 \%)$ & $56(22.7)$ & $4.47(3.82-6.84)^{* *}$ & $3.89(1.77-8.55)^{* *}$ \\
\hline No & $166(93.9 \%)$ & $11(6.1 \%)$ & 1 & 1 \\
\hline
\end{tabular}

${ }^{* *} P$ value $<0.05 ; \mathrm{CI}=$ confidence interval.

(71.9\%) [24], the Netherlands (57.3\%) [25], China (34.6\%) [29], and Nigeria (25.5\%) [28]. This difference may be due to the study population difference, in which previous studies were done among pregnant women, whereas this study was carried out in all reproductive age group women. In addition to this, the lowest awareness in current study may be due to low media coverage in Ethiopia and most of the participants had no higher level education. However, the result of this study is slightly higher than those of studies done in Nigeria (7.4\%) and Pakistan (6.7\%) [27]. This slight difference of women's awareness with regard to preconception folic acid supplementation is probably due to time variation between the current study and previous studies.

As Table 4 shows, women's educational status, monthly household income, having a chronic health problem, and a history of family planning use were significantly associated with women's awareness on preconception folic acid supplementation in both binary and multivariable logistic regression analysis. Women who had formal education, who had a chronic health problem, whose monthly household income was greater than one hundred US dollar, and who had a history of family planning use had good awareness on preconception folic acid supplementation.

Women's educational status was strongly associated with women's awareness on preconception folic acid supplementation. Women who had primary school education, secondary school education, and college and above were 3.9, 4 , and 4.8 times more likely had good awareness on preconception folic acid supplementation than women who had no formal education, respectively (AOR 3.94, CI 2.56-4.78; AOR 4.05, CI 2.79-6.94; and AOR 4.77, CI 1.85-6.98). This finding agrees with studies done in Nigeria, Lebanon, the Netherlands, China, and Pakistan [24, 25, 27-29]. The association may be explained by the fact that when individuals are being educated, they can easily read and understand information regarding folic acid and educated women might 
have interest to read, listen, and watch any information sources. In addition to this, even information related to folic acid supplementation may be discussed in school, so women who have formal education may have the chance to be aware.

The other important predictors of the current study were monthly household income (AOR 2.62, CI 2.05-7.76), having a chronic health problem (AOR 3.47, CI 2.68-5.98), and a history of family planning use (AOR 3.89, CI 1.778.55). The finding of this study is in line with studies done in Lebanon [24], the Netherlands [25], China [29], and France [31]. This is probably due to the fact that women who have a high income may have communication media and they may access information regarding folic acid. The association of having a chronic health problem and preconception folic acid awareness may be explained by the fact that women who had a chronic health problem may seek information about preconception health and pregnancy. Since pregnancy counseling, including preconception care, is given in the family planning unit, women who have used family planning methods might have some sort of information regarding preconception folic acid supplementation.

This study has different strengths. One of the strengths is that as it is community based, it is a representation of the true population. The other strength is the maximum sample size considered. But it has not been ended without limitation; one of the limitations of face-to-face interview is interviewer bias, and it might occur to some extent. Literatures relating to this specific title in African countries were very limited; especially, there was no literature which was done in Ethiopia regarding preconception folic acid consumption. Because of this problem, there was a difficulty in discussion part. As a quantitative study is not good to obtain better in-depth information what the participants have and feel, in-depth information was not studied.

\section{Conclusion}

The finding of this study confirmed that women's awareness on preconception folic acid supplementation is low. The finding of the current study identified that women's educational status, monthly household income, having a chronic health problem, and a history of family planning use were the predictors of women's awareness on preconception folic acid supplementation.

\section{Abbreviations}

AOR: Adjusted odds ratio

CI: Confidence interval

NTDs: Neural tube defects.

\section{Data Availability}

The datasets generated during the current study are available from the corresponding author based on reasonable request via email and phone call.

\section{Ethical Approval}

This study was approved by the Institutional Review Board of the College of Health Sciences, Mekelle University.

\section{Consent}

Informed written consent was obtained from all participants. Participation was on a voluntary basis and the collected information was kept confidential.

\section{Conflicts of Interest}

The authors declare that they have no conflicts of interest.

\section{Authors' Contributions}

Yitayal Ayalew Goshu contributed to inception, design, analysis, interpretation, and drafting of the research manuscript. Tewachew Muche Liyeh, Amare Simegn Ayele, Liknaw Bewket Zeleke, and Yohannes Tesfahun Kassie contributed to analysis, interpretation, and drafting of the research manuscript. All authors contributed to the final approval of the revised manuscript for publication.

\section{Acknowledgments}

Firstly, the authors are very grateful to Mekelle University for the approval of the ethical clearance and Debre Tabor University for its financial support for the study. Their sincere appreciations also go to data collectors and supervisors for their timely and honest collection of the required data. Finally, the authors would like to express their heartfelt thanks to the participants for their willingness to participate in the study, without whom this research would be impossible.

\section{References}

[1] A. Moore, W. Moumdle, D. O'Connor, D. Ray, and M. Van den Hof, "Pre-conception folic acid and multivitamin supplementation for the primary and secondary prevention of neural tube defects and other folic acid-sensitive congenital anomalies," SGOC Clinical Practice Guideline, vol. 37, no. 6, p. 324, 2015.

[2] A. J. Gaskins, T. L. Toth, and J. E. Chavarro, "Prepregnancy nutrition and early pregnancy outcomes," Current Nutrition Reports, vol. 4, no. 3, pp. 265-272, 2015.

[3] B. E. Bernstein, A. Meissner, and E. S. Lander, "The mammalian epigenome," Cell, vol. 128, no. 4, pp. 669-681, 2007.

[4] M. K. Moos, "Preconceptional health promotion: progress in changing a prevention paradigm," Journal of Perinatal \& Neonatal Nursing, vol. 12, no. 78, pp. 2-13, 2004.

[5] G. Teckie, A. Kromberg, and J. G. R Kromberg, "Neural tube defects in Gauteng, South Africa: recurrence risks and associated factors," South African Medical Journal, vol. 103, no. 12, pp. 973-977, 2013.

[6] T. Marchant, J. A. Schellenberg, R. Nathan et al., "Anaemia in pregnancy and infant mortality in Tanzania," Tropical Medicine and International Health, vol. 9, no. 2, pp. 262-266, 2004.

[7] F. Habib, E. H. Alabdin, M. Alenazy, and R. Nooh, "Compliance to iron supplementation during pregnancy," Journal of Obstetrics and Gynaecology, vol. 29, no. 6, pp. 487-492, 2009.

[8] E. Ekweagwu, A. E. Agwu, and E. Madukwe, "The role of micronutrients in child health: a review of literature," African Journal of Biotechnology, vol. 7, no. 11, pp. 1604-1611, 2008. 
[9] D. K. Tobias, C. Z. hang, J. Chavarro et al., "Prepregnancy adherence to dietary patterns and lower risk of gestational diabetes mellitus," American Journal of Clinical Nutrition, vol. 96, no. 2, pp. 289-295, 2012.

[10] A. Czeizel, M. Dobó, and P. Vargha, "Hungarian cohortcontrolled trial of periconceptional multivitamin supplementation shows a reduction in certain congenital abnormalities," Birth Defects Research Part A: Clinical and Molecular Teratology, vol. 70, no. 11, pp. 853-861, 2004.

[11] M. Viswanathan, K. A. Treiman, J. Doto, J. C. Middleton, E. J. L. Coker-Schwimmer, and W. K. Nicholson, "Folic acid supplementation for the prevention of neural tube defects," JAMA, vol. 2017, no. 317, p. 2, 2015.

[12] S. Timmermans, V. Jaddoe, A. Hofman et al., "Periconception folic acid supplementation, fetal growth and the risks of low birth weight and preterm birth: the Generation R Study," British Journal of Nutrition, vol. 102, no. 5, pp. 777-785, 2009.

[13] V. A. Hodgetts, R. K. Morris, A. Francis, J. Gardosi, and K. M. Ismail, "Effectiveness of folic acid supplementation in pregnancy on reducing the risk of small-for-gestational age neonates: a population study, systematic review and metaanalysis," BJOG: An International Journal of Obstetrics \& Gynaecology, vol. 122, no. 4, pp. 478-490, 2014.

[14] B. O. Verburg, E. A. Steegers, M. De Ridder et al., "New charts for ultrasound dating of pregnancy and assessment of foetal growth: longitudinal data from a population-based cohort study," Ultrasound in Obstetrics and Gynecology, vol. 31, no. 4, pp. 388-396, 2008.

[15] J. A. Greenberg, S. J. Bell, Y. Guan, and Y. H. Yu, "Folic acid supplementation and pregnancy: more than just neural tube defect prevention," Reviews in Obstetrics \& Gynecology, vol. 4, no. 5, pp. 2-9, 2011.

[16] J. Haidar, D. Melaku, and R. S. Pobocik, "Folate deficiency in women of reproductive age in nine administrative regions of Ethiopia: an emerging public health problem," South African Journal of Clinical Nutrition, vol. 23, no. 3, pp. 132-137, 2010.

[17] E. McLean, B. de Benoist, and L. H. Allen, "Review of the magnitude of folate and vitamin B12 deficiencies worldwide," Food and Nutrition Bulletin, vol. 29, no. 2, pp. S38-S51, 2008.

[18] R. E. Meyer, A. Wall, A. Morgan, J. Devine, and K. Powers, "Knowledge and use of folic acid among North Carolina women," North Carolina Medical Journal, vol. 63, no. 1, pp. 18-22, 2002.

[19] M. McGuire, B. Cleary, L. Sahm, and D. J. Murphy, "Prevalence and predictors of periconceptional folic acid uptake-prospective cohort study in an Irish urban obstetric population," Human Reproduction, vol. 25, no. 2, pp. 535543, 2010.

[20] L. Brough, G. A. Rees, M. A. Crawford, and E. K. Dorman, "Social and ethnic differences in folic acid use preconception and during early pregnancy in the UK: effect on maternal folate status," Journal of Human Nutrition and Dietetics, vol. 22, no. 2, pp. 100-107, 2009.

[21] A. S. Nzaku, "Assessing folic acid awareness and its usage for the prevention of neural tube defects among pregnant women in Jos, Nigeria," Journal of Basic and Clinical Reproductive Sciences, vol. 2, no. 1, p. 3, 2013.

[22] T. A. Lawal, O. B. Yusuf, and A. A. Fatiregun, "Knowledge of birth defects among nursing mothers in a developing country," African Health Sciences, vol. 15, no. 1, p. 180, 2015.

[23] Best Start Resource, "Preconception health care awareness and behaviors in Ontario," Center for Preconception Health, 2009.
[24] H. Tamim, G. Harrison, M. Atoui et al., "Preconceptional folic acid supplement use in Lebanon," Public Health Nutrition, vol. 12, no. 5, pp. 687-692, 2008.

[25] S. Temel, Ö. Erdem, T. A. J. J. Voorham, G. J. Bonsel, EA. P. Steegers, and S. Denktaş, "Knowledge on preconceptional folic acid supplementation and intention to seek for preconception care among men and women in an urban city: a population based cross-sectional study," BMC Pregnancy and Childbirth, vol. 15, no. 1, 2015.

[26] N. A. Al-Akour, R. Sou'Ub, K. Mohammad, and F. Zayed, "Awareness of preconception care among women and men: a study from Jordan," Journal of Obstetrics and Gynaecology, vol. 35, no. 3, pp. 246-250, 2015.

[27] M. Rehan, N. Mahmood, and S. B. Mazhar, "Knowledge, attitude and practices regarding periconceptional folic acid supplementation in a tertiary care hospital," Annals of International medical and Dental Research, vol. 11, no. 4, pp. 172-175, 2015.

[28] T. B. Rabiu, L. O. Tiamiyu, and B. S. Awoyinka, "Awareness of spina bifida and periconceptional use of folic acid among pregnant women in a developing economy," Child's Nervous System, vol. 28, no. 12, pp. 2115-2119, 2012.

[29] H. Huan Liang, M. Ma, S. F. Zhou, and X. Li, "Knowledge and use of folic acid for birth defect prevention among women of childbearing age in Shanghai, China: a prospective crosssectional study," Medical Science Monitor, vol. 17, no. 12, pp. PH87-PH92, 2011.

[30] Central Statistical Agency, AA National Survey, CSA, Ethiopia, 2015.

[31] Diabetes and Pregnancy Group in France, "Knowledge about preconception care in French women with type 1 diabetes," Diabetes \& Metabolism, vol. 31, p. 5, 2005. 


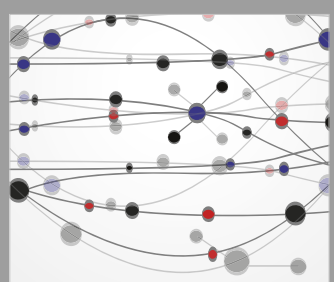

The Scientific World Journal
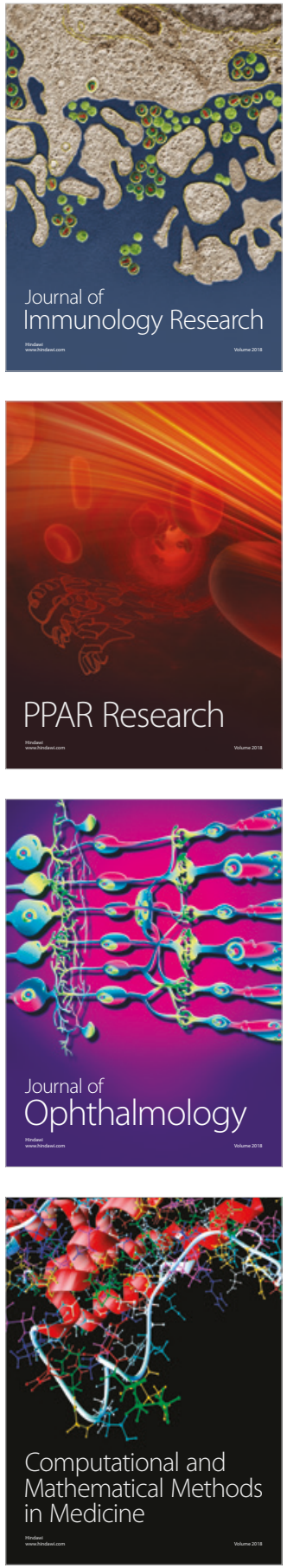

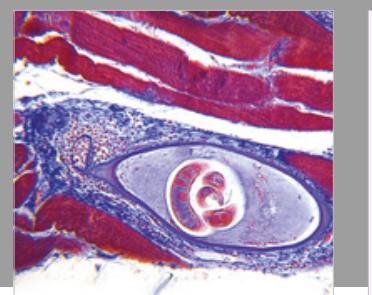

Gastroenterology Research and Practice

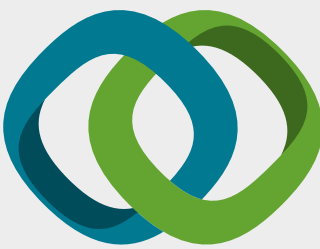

\section{Hindawi}

Submit your manuscripts at

www.hindawi.com
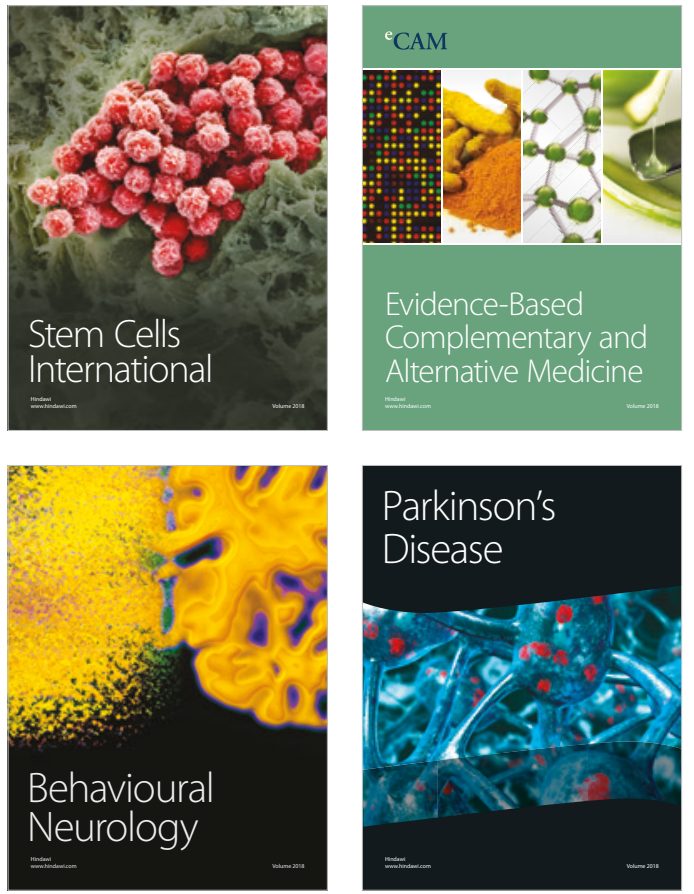

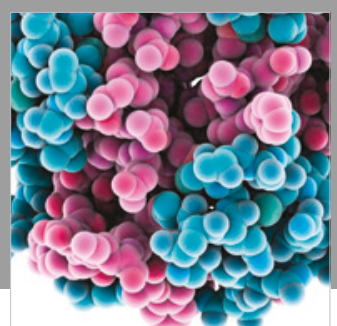

ournal of

Diabetes Research

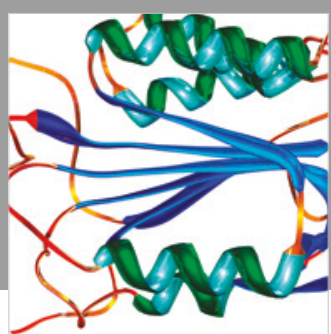

Disease Markers
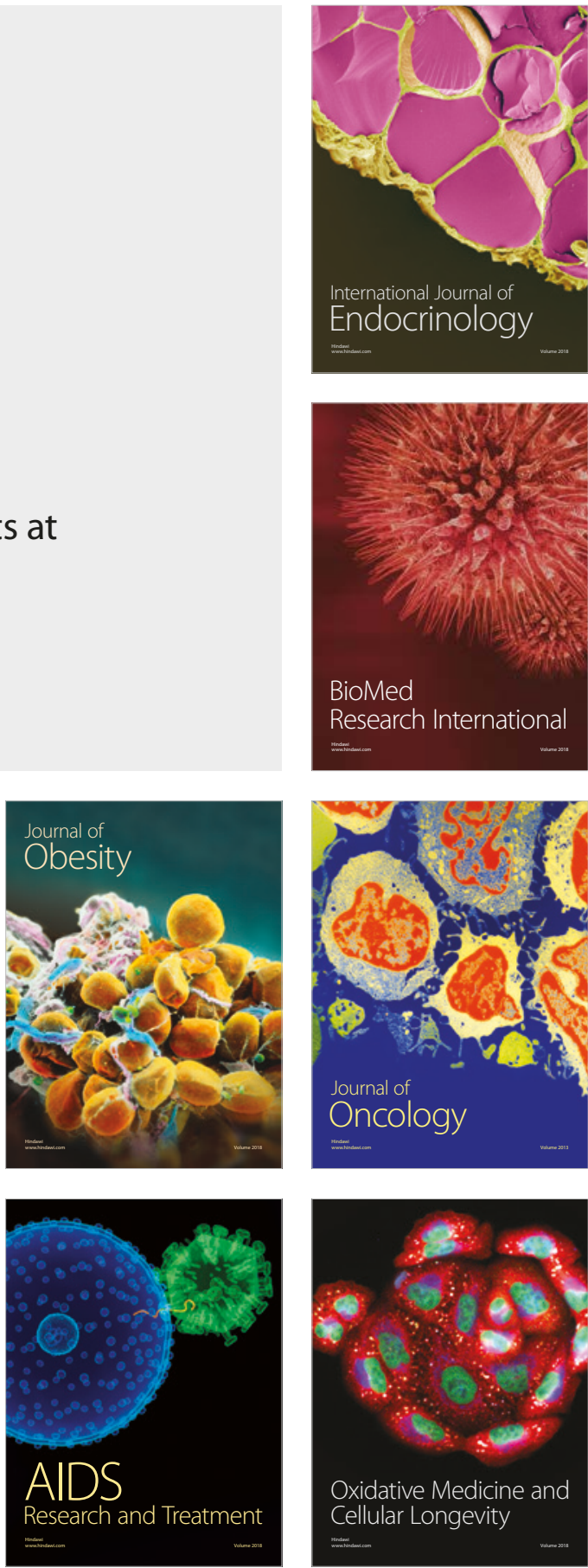